\title{
Pengenalan Dasar Microsoft Office Excel 2007 Bagi Guru-Guru Paud Kecamatan Tambun Selatan
}

\author{
Muhammad Rusli'), Jullend Gatc(4), Alwi Adib Novianto ${ }^{3)}$, Lucky Hartanto Salim ${ }^{4)}$ \\ System Informasi, Institut Teknologi dan Bisnis Kalbis \\ Jalan Pulomas Selatan Kav. 22, Jakarta 13220 \\ ${ }^{1)}$ muhammad.rusli@kalbis.ac.id, \\ 2)jullend.gatc@kalbis.ac.id \\ ${ }^{3)}$ novianto.adib@gmail.com \\ 4)Luckyhartantos@gmail.com
}

\begin{abstract}
The training provided for PAUD teachers in Tambun Selatan District aims to improve the ability of these teachers to use Microsoft Office, especially Microsoft Excel. There are various kinds of obstacles faced by PAUD teachers in South Tambun District, including the use of the DAPODIK management application program, the spreadsheet program, namely Microsoft Excel 2007 and the use of the internet and the website. In applying these applications can help teachers make student data reports every year. In connection with this and in order to realize one of the Tri Dharma of Higher Education, namely community service, the Kalbis Institute Information System study program held a training program for PAUD teachers in Tambun Selatan Subdistrict on Microsoft Office Excel 2007 application training.
\end{abstract}

Keywords: DAPODIK, PAUD, PKM, Training

Abstrak: Pelatihan yang diberikan bagi guru-guru PAUD Kecamatan Tambun Selatan bertujuan untuk meningkatkan kemampuan guru-guru tersebut dalam penggunaan Microsoft Office khususnya Microsoft Excel. Terdapat berbagai macam kendala yang dihadapi oleh guru-guru PAUD di Kecamatan Tambun Selatan antara lain penggunaan program aplikasi manajemen DAPODIK, program spreadsheet yaitu Microsoft Excel 2007 dan pemanfaatan internet serta website. Dalam penerapannya aplikasi-aplikasi tersebut dapat membantu guru-guru membuat laporan data peserta didik setiap tahunnya. Sehubungan dengan hal tersebut dan dalam rangka mewujudkan salah satu Tri Dharma Perguruan Tinggi yaitu pengabdian kepada masyarakat, program studi Sistem Informasi Kalbis Institute mengadakan program pelatihan bagi guruguru PAUD Kecamatan Tambun Selatan tentang pelatihan aplikasi Microsoft Office Excel 2007.

Kata kunci: DAPODIK, PAUD, pelatihan, PKM

\section{PENDAHULUAN}

Pendidikan anak usia dini (PAUD) adalah jenjang pendidikan sebelum jenjang pendidikan dasar yang merupakan suatu upaya pembinaan yang ditujukan bagi anak sejak lahir sampai dengan usia enam tahun yang dilakukan melalui pemberian rangsangan pendidikan untuk membantu pertumbuhan dan perkembangan jasmani dan rohani agar anak memiliki kesiapan dalam memasuki pendidikan lebih lanjut, yang diselenggarakan pada jalur formal, nonformal, dan informal. (Direktorat Jenderal Pendidikan
Anak Usia Dini dan Pendidikan Masyarakat, 2015). Himpaudi Kecamatan Tambun Selatan terdapat 240 PAUD, terbentuk melalui Musyawarah Cabang (MUSCAB) Kecamatan Tambun Selatan yang dilaksanakan pada 11 Maret 2015. Kepengurusan dilantik dan dikukuhkan melalui Pelantikan Bersama Himpaudi 23 Cabang Kecamatan Se Kabupaten Bekasi di Gedung Serbaguna Cikarang Selatan pada tanggal 11 Oktober 2015.

Visinya adalah Terwujudnya Tenaga Pendidik dan Kependidikan Anak Usia Dini yang Trampil, Profesional, Berakhlak Mulia dan Mandiri. Misinya 
adalah (1) Menghimpun tenaga pendidik dan kependidikan anak usia dini Indonesia di Cabang Kecamatan Tambun Selatan untuk mencerdaskan bangsa; (2) Meningkatkan profesionalitas tenaga pendidik dan kependidikan anak usia dini Indonesia; (3) Meningkatkan kesejahteraan tenaga pendidik dan kependidikan anak usia dini Indonesia di Cabang Kecamatan Tambun Selatan; dan (4) Menjalin kerjasama dan kemitraan dengan berbagai pihak untuk memajukan dan daya juang Himpadi. Tujuannya adalah sebagai wadah organisasi profesi yang bertujuan menghimpun aspirasi serta meningkatkan profesionalisme pendidik dan tenaga kependidikan anak usia dini Indonesia sebagai wadah untuk: (1) Mempersatukan pendidik dan tenaga kependidikan anak usia dini; (2) Meningkatkan kualitas pendidik dan tenaga kependidikan anak usia dini; dan (3) Memperjuangkan peningkatan kesejahteraan dan perlindungan bagi pendidik dan tenaga kependidikan anak usia dini. (Negeri, 2016).

Dalam pelaksanaan kegiatan PAUD di Kecamatan Tambun Selatan terdapat beberapa kendala yang dihadapi yaitu, dalam pengelolaan data pokok pendidikan PAUD, pemahaman tentang komputer dan internet, aplikasi Dapodik, surat menyurat dalam kegiatan organisasi, serta persiapan bahan ajar dalam proses belajar mengajar. Keterlibatan teknologi komputer sebagai alat untuk memudahkan suatu pekerjaan juga dapat meningkatkan efisiensi waktu dan tenaga dalam menyelesaikan pekerjaan. Namun masih sangat disayangkan bahwa penggunaan teknologi komputer di PAUD Kecamatan Tambun Selatan sangatlah minim. Hal ini disebabkan oleh keterbatasan pengetahuan teknologi yang dimiliki oleh guru-guru PAUD dan kepala sekolah dalam bidang komputer.

Hasil dari wawancara dengan Ketua HIMPAUDI Kecamatan Tambun Selatan yaitu salah satu hambatan dalam administrasi PAUD dan proses belajar mengajar adalah keterbatasaan fasilitas yang dimiliki dan akses terhadap ilmu pengetahuan yang terus berkembang, antara lain keterampilan dalam pengolahan data yang terkait dengan proses administrasi belajar mengajar. Terdapat berbagai macam kendala yang dihadapi oleh guru-guru PAUD di Kecamatan Tambun Selatan antara lain penggunaan program aplikasi manajemen DAPODIK, program spreadsheet yaitu Microsoft Excel 2007 dan pemanfaatan internet serta website. Dalam penerapannya aplikasi-aplikasi tersebut dapat membantu guru-guru membuat laporan data peserta didik setiap tahunnya. Sehubungan dengan hal tersebut dan dalam rangka mewujudkan salah satu Tri
Dharma Perguruan Tinggi yaitu pengabdian kepada masyarakat, program studi Sistem Informasi Kalbis Institute akan mengusulkan program pelatihan bagi guru-guru PAUD Kecamatan Tambun Selatan tentang pelatihan aplikasi Microsoft Office Excel 2007. Pelatihan kepada para guru-guru PAUD Kecamatan TambunSelatanmengenai dasar-dasarMicrosoftExcel sebagai sarana pendukung proses pembelajaran di sekolah dan peningkatan kemampuan guru-guru akan dilaksanakan pada tanggal 13 November 2019 di KB BAITURROHIM, JL. Zamrud Raya Perum Metland Tambun RT 001/008 Desa Tambun, Kecamatan Tambun Selatan, Kabupaten Bekasi dengan materi pelatihan Pengenalan Aplikasi Microsoft Office dan Pengoperasian Aplikasi Microsoft Excel 2007.

Pengabdian Kepada masyarakat ini dilakukan KB BAITURROHIM, JL. Zamrud Raya Perum Metland Tambun RT 001/008 Desa Tambun, Kecamatan Tambun Selatan, Kab. Bekasi. Dapat dilihat pada Gambar 1.

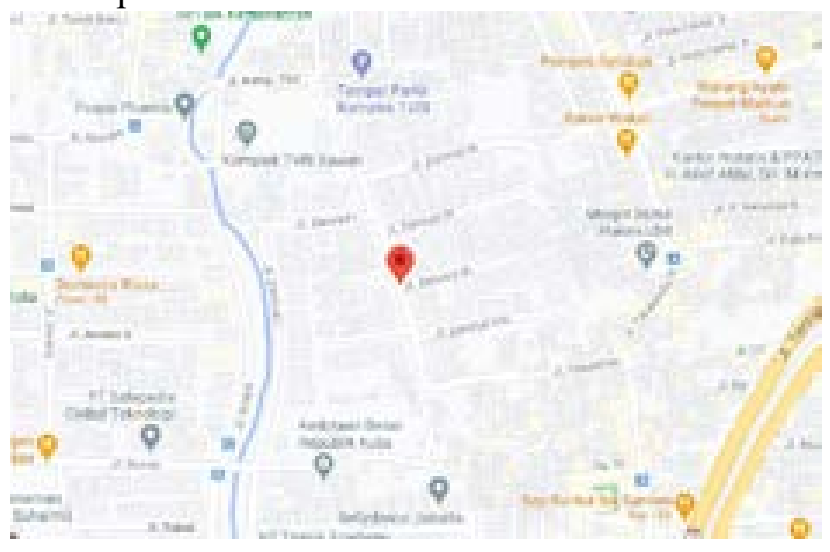

Gambar 1. Lokasi mitra

\section{METODE PELAKSANAAN}

\section{A. Metode dan Pendekatan}

Sebagai program studi yang terkait dengan bidang teknologi dan bisnis maka Prodi Sistem Informasi Kalbis Institute sangat antusias untuk ikut berpartisipasi dalam kegiatan PKM dengan HIMPAUDI Kecamatan Tambun Selatan.

Berdasarkan Visi HIMPAUDI Kecamatan Tambun Selatan adalah "Terwujudnya Tenaga Pendidik dan Kependidikan Anak Usia Dini yang Trampil, Profesional, Berakhlak Mulia dan Mandiri” serta salah satu misinya adalah "Meningkatkan profesionalitas tenaga pendidik dan kependidikan anak usia dini Indonesia" maka Prodi Sistem Informasi mengusulkan untuk memberikan pelatihan "Pengenalan Dasar Microsoft Office Excel 2007 Bagi Guru-Guru PAUD Kecamatan Tambun Selatan". Pelatihan ini akan sangat mendukung dan membantu 
guru-guru PAUD Kecamatan Tambun Selatan untuk meningkatkan profesionalitas sebagai pendidik.

Dari kegiatan pelatihan ini, Prodi Sistem Informasi mengharapkan nantinya para guru PAUD Kecamatan Tambun Selatan punya keahlian secara praktikal untuk membuat pelaporan menggunakan Microsoft Excel2007. Dari keahlian itu maka nantinya para guru PAUD Kecamatan Tambun Selatan dapat membuat pelaporan mengenai data tenaga pendidik, peserta didik, dan kegiatan pembelajaran ke tingkat kecamatan atau kabupaten menggunakan Microsoft Excel 2007. (Rusli \& Edi Winarso, 2020).

Manfaat Kegiatan Bagi Prodi Sistem Informasi: Pemenuhan kewajiban Pengabdian pada Masyarakat bagi Dosen Prodi; Meningkatkan keahlian dosen melalui proses sharing keahlian bagi mitra; Memperbanyak relasi dengan mitra untuk berbagai fungsi-fungsi positif; dan Memberikan pengalaman baru bagi dosen-dosen Prodi Sistem Informasi mengenai pemanfaatan teknologi untuk membuat pelaporan menggunakan Microsoft Excel 2007.

Manfaat Kegiatan Bagi Guru-guru PAUD Tambun Selatan: Meningkatkan keahlian secara praktikal mengenai Microsoft Power Point 2007; Memberikan pengenalan mengenai konsep dasar dan perangkat pendukung Microsoft Excel 2007; Memberikan peluang bagi mitra untuk mengembangkan presentasi menggunakan Microsoft Excel 2007; dan Memberikan pemahaman baru mengenai dunia kampus Kalbis Institute.

\section{B. Waktu Efektif Pelaksanaan}

Waktu efektif pelaksanaan kegiatan pengabdian kepada masyarakat dengan tema "Pengenalan Dasar Microsoft Office Excel 2007 Bagi Guru-Guru PAUD Kecamatan Tambun Selatan" yang dilaksanakan pada 13 November 2019.

\section{HASIL DAN PEMBAHASAN}

\section{A. Evaluasi Pelaksanaan PKM}

Kegiatan pelatihan yang akan dilaksanakan bulan November 2019 sebagai berikut: Perencanaan kegiatan PKM. Rencana ini didiskusikan dalam rapat Tim Dosen Program Studi Sistem Informasi Fakultas Industri Kreatif Institut Teknologi dan Bisnis Kalbis yang tergabung kedalam Tim Pengabdian Kepada Masyarakat (PKM) pada 10 Oktober 2019 pukul 16.00 - 18.00 di ruang dosen Lantai 2 Kampus Institut Teknologi dan Bisnis Kalbis Jalan Pulomas Selatan Kav.22 Jakarta Timur. Diskusi ini untuk membicarakan PKM yang merupakan salah satu wujud Tri Dharma Perguruan Tinggi. Hasilnya adalah kesepakatan untuk melakukan PKM dengan HIMPAUDI Kecamatan Tambun Selatan.

Observasi dan Koordinasi tim PKM ke HIMPAUDI Kecamatan Tambun Selatan tanggal 25 Oktober 2019 pukul 08.00 - 17.00 untuk: Perkenalan kegiatan PKM Prodi Sistem Informasi oleh tim PKM kepada mitra; Pengenalan profil pengurus HIMPAUDI Kec. Tambun Selatan; Pemberian saransaran dari para pengurus HIMPAUDI Kecamatan Tambun Selatan agar kegiatan pengabdian masyarakat tepat sasaran dan bermanfaat bagi pengurus HIMPAUDI Kecamatan Tambun Selatan; Identifikasi permasalahan spesifik yang sedang dihadapi mitra; Koordinasi tema pelatihan yang dibutuhkan oleh mitra; dan Koordinasi waktu dan tempat pelaksanaan kegiatan PKM.

Dalam rapat Tim PKM pada tanggal 28 Oktober 2019 jam 13.00 - 17.00 di ruang dosen Lantai 2 Kampus Institut Teknologi dan Bisnis Kalbis Jalan Pulomas Selatan Kav.22 Jakarta Timur dibicarakan program dan tema PKM yang diberikan bagi guruguru PAUD Kecamatan Tambun Selatan. Hasilnya adalah kesepakatan untuk mengadakan PKM dengan tema "Pengenalan Dasar Microsoft Office Excel 2007 Bagi Guru-Guru PAUD Kecamatan Tambun Selatan" pada tanggal 13 November bertempat di KB BAITURROHIM, Tambun Selatan.

Pembuatan proposal PKM "Pengenalan Dasar Microsoft Office Excel 2007 Bagi Guru-Guru PAUD Kecamatan Tambun Selatan" tanggal 30 Oktober 2019 pukul $08.00-17.00$ oleh tim PKM. Pembuatan materi pelatihan PKM "Pengenalan Dasar Microsoft Office Excel 2007 Bagi Guru-Guru PAUD Kecamatan Tambun Selatan" tanggal 31 Oktober 2019 pukul 08.00 - 17.00 oleh tim PKM. Kegiatan pelatihan dilaksanakan selama satu hari yaitu tanggal 13 November 2019 pukul 08.00 - 17.00 WIB, bertempat di KB BAITURROHIM, Tambun Selatan. Pelatihan akan diberikan oleh Tim PKM dari Prodi Sistem Informasi yang berjumlah sebanyak tiga orang dosen

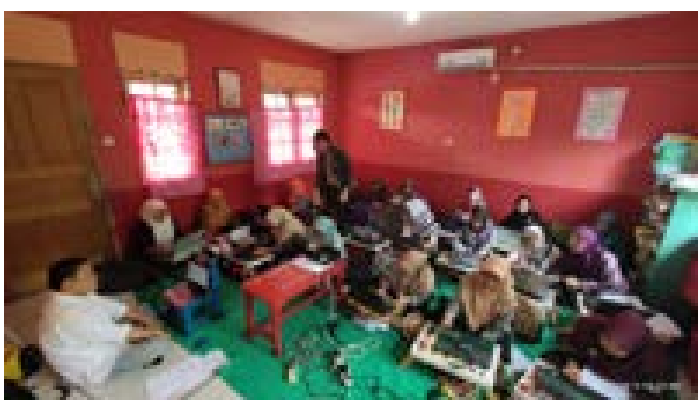

Gambar 1. Pelaksanaan 1 
dan dua mahasiswa. Peserta pelatihan adalah guruguru PAUD Tambun Selatan. Pelaksanaan kegiatan seperti pada Gambar 1, Gambar 2, dan Gambar 3.

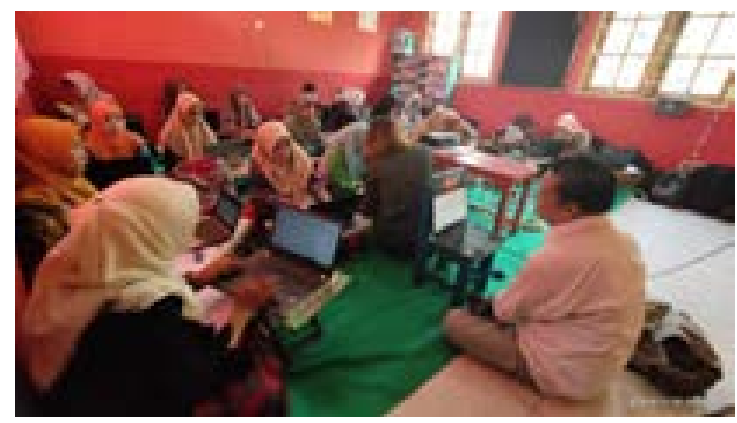

Gambar 2. Pelaksanaan 2

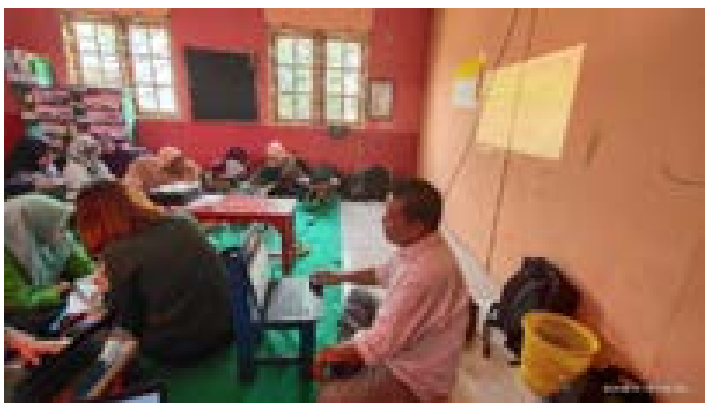

Gambar 3. Pelaksanaan 3

\section{B. Indikator Keberhasilan Kegiatan PKM}

Indikator keberhasilan kegiatan PKM ini yang dilakukan pada Tanggal 13 november 2019 dari Jam 08.00 - 17.00, bahwa kegiatan in sudah terlaksana dengan baik sesuai dengan jadwal yang sudah ditentukan. Semua peserta pelatihan berpartisipasi aktif dalam kegiatan pelatihan ini. Guru-guru PAUD sangat antusias dalam kegiatan pelatihan ini. Dari kuesioner yang diisi oleh peserta pelatihan diperoleh rata-rata 6,11 ini menunjukkan bahwa pelaksanaan kegiatan PKM tersebut baik

\section{Keberlanjutan Kegiatan PKM}

Kegiatan PKM di HIMPAUDI Kecamatan Tambun Selatan akan dilanjutkan sesuai dengan waktu yang disepakati antara Mitra dengan tim PKM dari Program Studi Sistem Informasi. Kegiatan ini akan dilanjutkan sesuai dengan kesepakatan (MOU).

\section{Peran Serta Mitra Dalam Kegiatan}

Peran serta mitra yaitu pendiri, guru dan pengurus HIMPAUDI Kecamatan Tambun Selatan dalam upaya memahami dan menyadari tentang pentingnya mengikuti pelatihan yang diberikan oleh tim PKM prodi Sistem Informasi Kalbis Institute adalah dengan melakukan: Diskusi ketua, pengurus, dan guru HIMPAUDI Kecamatan Tambun Selatan dengan Tim PKM yang merupakan dosen-dosen Prodi Sistem Informasi Fakultas Industri Kreatif Kalbis Institute untuk membicarakan kegiatan PKM; dan Sekitar 36 peserta yang merupakan guru-guru HIMPAUDI Kecamatan Tambun Selatan yang telah menghadiri pelatihan yang diberikan oleh Tim PKM tanggal 13 November 2019 yang bertempat di di KB BAITURROHIM JL. Zamrud Raya Perum Metland Tambun RT 001/008 Desa Tambun, Kecamatan Tambun Selatan, Kabupaten Bekasi, Jawa Barat.

\section{E. Peranan/Tugas Mitra dalam Kegiatan}

Peran /tugas mitra dalam kegiatan PKM ini adalah sebagai berikut: 1) Menyediakan kelas untuk tempat pelatihan; 2) Mengundang guruguru HIMPAUDI untuk mengikuti pelatihan yang diberikan; 3) Menghadiri seluruh rangkaian kegiatan PKM, mulai dari pembukaaan, pelatihan sampai penutupan kegiatan; 4) Memberikan kelengkapan surat dan dokumen lainnya yang dibutuhkan oleh tim PKM; 5) Menyiapkan makan siang untuk peserta dan tim PKM.

\section{KESIMPULAN}

Pelatihan yang diberikan kepada Guru-guru PAUD memberikan pengetahuan dasar tentang aplikasi omputer Microsoft Excel 2007 mengenai pembuatan laporan megenai tenaga pendidik, peserta didik, dan proses pembeajaran dalam rangka meningkatkan profesionalisme para guru dalam kegiatan belajar mengajar.

\section{DAFTAR PUSTAKA}

Direktorat Jenderal Pendidikan Anak Usia Dini dan Pendidikan Masyarakat. (2015, Januari 01). Retrieved November 6, 2019, from http://www.paudni. kemdikbud.go.id/dpn/

Negeri, P. (2016, Mei 26). Satuan Pendidikan Anak Usia Dini (PAUD). Retrieved November 6, 2019, from Padamu Pendidikan Indonesia: https://www.padamu.net/ pendidikan-anak-usia-dini

Rusli, M., \& Edi Winarso, D. P. (2020). Pelatihan Microsoft Powerpoint Dasar Bagi Guru Guru Paud Kabupaten Bekasi. ABDIMAS, Jurnal Pengabdian Kepada Masyarakat, 1(1), 12-15. 